\title{
Distribution of circulating tumor DNA in lung cancer: analysis of the primary lung and bone marrow along with the pulmonary venous and peripheral blood
}

\author{
Taichiro Goto ${ }^{1, *}$, Yosuke Hirotsu ${ }^{2,}{ }^{*}$, Kenji Amemiya ${ }^{2}$, Takahiro Nakagomi ${ }^{1}$, \\ Daichi Shikata $^{1}$, Yujiro Yokoyama ${ }^{1}$, Kenichiro Okimoto ${ }^{2}$, Toshio Oyama ${ }^{3}$, Hitoshi \\ Mochizuki² and Masao Omata ${ }^{2,4}$ \\ ${ }^{1}$ Lung Cancer and Respiratory Disease Center, Yamanashi Central Hospital, Yamanashi, Japan \\ ${ }^{2}$ Genome Analysis Center, Yamanashi Central Hospital, Yamanashi, Japan \\ ${ }^{3}$ Department of Pathology, Yamanashi Central Hospital, Yamanashi, Japan \\ ${ }^{4}$ University of Tokyo, Tokyo, Japan \\ *Taichiro Goto and Yosuke Hirotsu contributed equally to this study \\ Correspondence to: Taichiro Goto, email: taichiro@1997.jukuin.keio.ac.jp \\ Keywords: circulating tumor DNA, distribution, lung cancer, next-generation sequencing, plasma \\ Received: October 19, $2016 \quad$ Accepted: June 02, $2017 \quad$ Published: July 25, 2017 \\ Copyright: Goto et al. This is an open-access article distributed under the terms of the Creative Commons Attribution License 3.0 \\ (CC BY 3.0), which permits unrestricted use, distribution, and reproduction in any medium, provided the original author and source \\ are credited.
}

\section{ABSTRACT}

Circulating tumor DNA (ctDNA), extracted from plasma, is a non-invasive surrogate biomarker. However, the distribution of ctDNA in the body still remains to be elucidated. In this study, resected lung tumors, with simultaneous blood and bone marrow samples, were analyzed to elucidate the distribution of ctDNA. Rib bone marrow, pulmonary venous blood (Pul.V) and peripheral blood (Peri.B) were obtained from 30 patients. The liquid samples were divided into cell pellets and supernatant by centrifugation; a total of 212 DNA samples were subjected to massively parallel sequencing. ctDNA was detected in 5 patients. Given that the frequency of mutations in the primary tumor was considered to be $100 \%$, those in the other specimens were as follows; Pul.V plasma $20 \%$, Peri.B plasma $11 \%$, and the other samples $0 \%$. Furthermore, ctDNA reflected the predominant mutations in the primary lesion. Clinically, the presence of ctDNA was associated with significantly poorer survival. These results suggest ctDNA "spill over" into an immediate outflow tract (Pul.V), and from there is disseminated to the entire body. Thus, it can be inferred that ctDNA reflects the cancer progression and could function as a prognostic marker.

\section{INTRODUCTION}

Cancer may be described as a disease of genetic and epigenetic mutations [1]. Recent genome sequencing studies have revealed the genetic landscape of lung cancers and presented opportunities to identify specific biomarkers [2-4]. Circulating cell-free DNA in plasma or other body fluids has potentially transformative applications as a newgeneration and non-invasive surrogate biomarker in cancer diagnosis and treatment [1, 5-10].
Serum-based protein biomarkers, such as the carcinoembryonic antigen and squamous cell carcinoma (SCC) antigen, are commonly used in the clinical setting; however, these markers are also produced by normal cells to a certain extent and thus do not always reflect cancer progression in all patients with lung cancer [11-13]. In contrast, cell-free DNA containing the tumor-specific variants, also known as circulating tumor DNA (ctDNA), is exclusively released by cancer cells, and thus is suggested to be a more specific and informative biomarker [1]. 
ctDNA is composed of small nucleic acid fragments and is released from tumor cells into the blood [14]. This release of ctDNA takes place through a variety of physiological cellular events, such as apoptosis, necrosis, and secretory release [10]. ctDNA is detectable in the plasma and serum of patients with advanced cancer [15-21].

Therefore, one of the most immediate applications of ctDNA is what has been termed "liquid biopsy" [9, $10,16,22-24]$. Sensitive methods for detecting tumorderived mutations in plasma may find applications in early detection, screening, disease prognosis, monitoring tumor dynamics over time, and the detection of minimal residual disease or resistant mutations [23, 25-28]. Although ctDNA has been detected in the peripheral blood, the mechanism and rate of release, as well as its distribution and natural course in the body, are still unknown.

In this study, we sought to verify the presence of ctDNA in operable primary lung cancer and to clarify its natural course and pathophysiology by determining its body distribution pattern. On the basis of previous studies on circulating tumor cells (CTCs) as well as disseminated tumor cells [29-35], we hypothesized that ctDNA exists in the pulmonary venous blood (Pul.V), peripheral blood (Peri.B), and/or bone marrow fluid (BM). Based on the hypothesis that ctDNA exists in these sites, even in relatively early lung cancers, we analyzed the distribution of ctDNA in the body. In addition, we analyzed the mutational profiles, pathohistology, and clinical characteristics of ctDNA-positive lung cancers, as well as the correlation between these findings and the postoperative survival rate. We also examined whether this minimal residual disease detection with ctDNA would be able to accurately identify patients at risk of cancer relapse.

\section{RESULTS}

\section{The number of mutations found in the primary lesions}

Thirty-two primary tumors from 30 patients were analyzed by deep sequencing, which detected $11.1 \pm$ 3.3 mutations with an allele fraction $(\mathrm{AF}) \geq 1 \%$, along with $2.7 \pm 0.4$ mutations with an $\mathrm{AF} \geq 20 \%$ (Figure $1 \mathrm{~A}$ ). A comparison of the adenocarcinomas and the SCC histological types revealed no significant difference in the number of mutations with $\mathrm{AF} \geq 1 \%$. However, when only mutations with AF $\geq 20 \%$ were targeted, SCCs were found to harbor significantly more mutations than adenocarcinomas (Figure 1B). A comparison between smokers and non-smokers also showed that the number of mutations, especially significant mutations with $\mathrm{AF} \geq$ 20\%, was significantly larger among smokers (Figure 1C).

\section{Functional pathways of mutations found in lung cancers}

The significant mutations (AF $\geq 20 \%$ ) that were detected in all 30 patients are shown in Figure 2 (Supplementary Tables 1 and 2). Although point mutations were most prevalent in general, frameshift and nonsense mutations were also frequently detected in tumor suppressor genes such as RB1, PTEN, and TP53. A comparison of the frequency of mutations in the functional pathways revealed that the RAS and TP53 pathways were affected in $>50 \%$ of the cases, and that the frequency was significantly higher in these pathways than in the others (Supplementary Figure 1A). When the frequencies of the affected pathways were compared between adenocarcinomas and SCCs, the RAS pathway was found to be affected significantly more frequently in adenocarcinomas, while the chromatin remodeling, epigenetic, transcription, and TP53 pathways were affected significantly more frequently in SCCs (Supplementary Figure 1B). A comparison of cancers in smokers and non-smokers showed that the epigenetic pathway was affected significantly more frequently in lung cancers in smokers than non-smokers (Supplementary Figure 1C).

\section{Frequency of the ctDNA mutations in the different sampling sites}

Using the mutations detected in the primary lesion as markers, we sought to detect identical mutations in the blood and BM fluid samples. In five of the 30 patients, identical mutations were detected in the ctDNA of Pul.V, and Peri.B plasma, and individual tumors released more than one type of ctDNA mutation (Table 1 and Figure 3A-3E). Identical mutations were not detected in the cell fractions or BM fluid. The AFs of the identical mutations detected in these five cases were compared among the primary lesion, Pul.V plasma, Peri.B plasma, supernatant of the BM suspensions, and cell fractions. Tumor DNA mutations were detected in three of these, the primary lesion, the Pul.V plasma, and the Peri.B plasma. The AF gradient for all the mutations was highest in the samples from the primary lesion, followed by that for mutations in the Pul.V plasma and then, the Peri.B plasma. Eighteen and 11 mutants were detected in the Pul.V plasma and Peri.B plasma samples, respectively (Table 1). Furthermore, of the 18 mutants detected in the Pul.V plasma samples, seven (38.9\%) were not detected in the Peri.B plasma samples. Considering the primary tumor as $100 \%$, the frequencies of the mutations were as follows: Pul.V plasma, 20\%; Peri.B plasma, 11\%; Pul.V pellet, 0\%; Peri.B pellet, 0\%; BM supernatant, $0 \%$; and BM pellet, $0 \%$ (Figure $3 \mathrm{~F}$ ). 


\section{Correlation between the frequency of tumor- derived DNA in the primary lesion and that in the ctDNA}

We examined the correlation between the AF values of mutations in the primary lesion and plasma samples to investigate the etiology of tumor-derived DNA in the body. The AF of the mutations in the primary lesion correlated significantly with that of the mutations in the ctDNA detected in the Pul.V and Peri.B plasma $(\mathrm{R}=0.57$, $p<0.05$ and $\mathrm{R}=0.54, p<0.05$, respectively) (Figure 4A and 4B). This suggested that ctDNA was more likely to be released into the blood when the mutations in the primary lesions had a higher AF value. A significant correlation was observed between the AF values of the mutations in the ctDNA detected in the Pul.V and Peri.B plasma $(\mathrm{R}=$ $0.98, p<0.05)$. The AF of mutations in the ctDNA in the Pul.V plasma was higher than that in the Peri.B plasma.
The approximation formula was $Y=1.42 X+1.81(X$ : AF of the ctDNA in the Peri.B plasma; $Y$ : AF of the ctDNA in the Pul.V plasma) (Figure 4C).

\section{Comparison of the number of mutations and functional pathways in cancers with and without ctDNA release}

The number of mutations in lung cancers that released ctDNA into the plasma was compared with that in lung cancers that did not. With an AF threshold of either $1 \%$ or $20 \%$, the number of mutations was significantly larger in lung cancers that released ctDNA (Table 2).

The epigenetic and transcription pathways were affected significantly more frequently in cancers that released ctDNA into the plasma than in those that did not (Supplementary Figure 2, $p<0.05$ ).
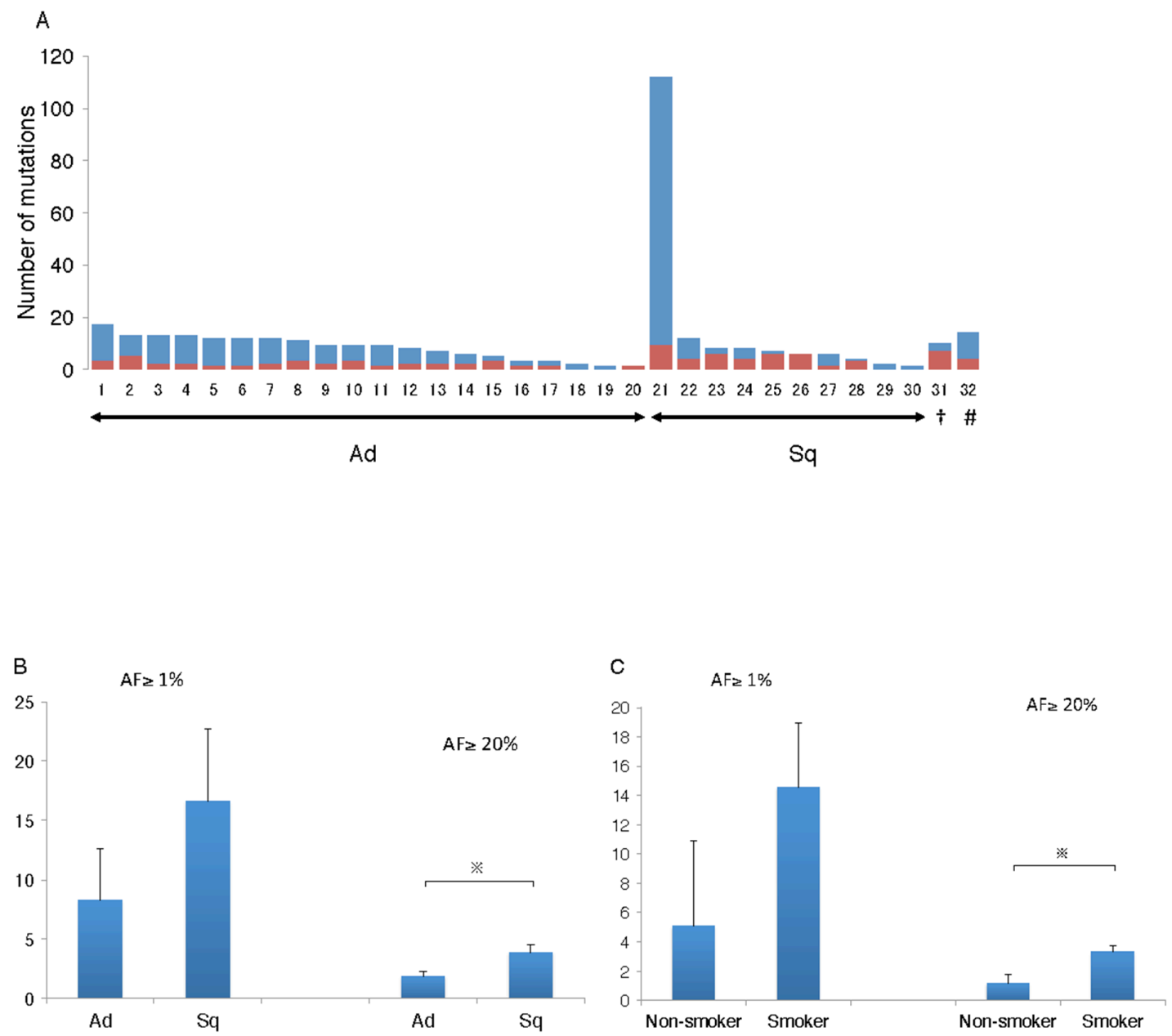

Figure 1: Number of mutations identified in the primary lesion. (A) Deep sequencing of the samples revealed the number of mutations to be $11.1 \pm 3.3$ and $2.7 \pm 0.4$ with $\mathrm{AF} \geq 1 \%$ and $\mathrm{AF}>20 \%$, respectively. Red bar indicates number of mutations with $\mathrm{AF} \geq 20 \%$. Blue bar indicates number of mutations with the limitation $20>\mathrm{AF} \geq 1 \%$. $\uparrow$, small cell carcinoma; \#, large cell neuroendocrine carcinoma; Ad, adenocarcinoma; Sq, squamous cell carcinoma. (B) Squamous cell carcinoma contained significantly larger number of significant mutations with $\mathrm{AF} \geq 20 \%$, compared to adenocarcinoma. Ad, adenocarcinoma; Sq, squamous cell carcinoma; $\ldots, p<0.05$. (C) Smokers had significantly larger number of significant mutations with $\mathrm{AF} \geq 20 \%$ than non-smokers. $※, p<0.05$. 


\section{Number of mutations in the specimens, including the lung cancer-nonspecific ones}

In comparison with the total number of cell-free mutations with $\mathrm{AF} \geq 1 \%$ that were detected in the samples, including mutations that did not correspond to those detected in the primary lung cancer lesion, the number of mutations was significantly larger in the samples obtained from the primary lesion and Peri.B plasma than in those obtained from the other 4 samples (Figure 5, $p<0.05$; Supplementary Table 3 ). In particular, the number of mutations detected in Peri.B plasma was significantly larger than that in Pul.V plasma (Figure 5, $p<0.05$ ).

\section{Correlations between clinical conditions and ctDNA}

The clinical aspects of lung cancer were compared between ctDNA-positive and ctDNA-negative lung cancers (Table 3 and Supplementary Table 1). It was found that men and smokers were significantly more likely to be positive for ctDNA (Table 3, $p<0.05$ ). Moreover, the tumor size was significantly larger and, histologically, the proportion of SCCs was significantly higher for ctDNApositive lung cancers (Table $3, p<0.05$ ). Patients with ctDNA-positive lung cancer were found to be more likely to have advanced-stage disease and to have undergone non-curative surgery (Table 3, $p=0.08$ and $p=0.09$, respectively). Pathological vessel and lymphatic invasions were not associated with the presence of ctDNA. Through a multivariate analysis, we identified size, histology, and pathological stage of the cancer as factors that affect ctDNA release $(p<0.05)$; no correlations were observed for patient age, gender, and smoking habit.

\section{Survival rate of lung cancer patients with or without plasma ctDNA}

The five patients with plasma ctDNA had significantly poorer outcomes than 25 patients without ctDNA in their plasma (Figure 6A). Two patients who died of cancer had mutated plasma ctDNA with extremely high AF (Table 1 and Supplementary Table 1).

\section{Postoperative changes in the plasma ctDNA}

The ctDNA levels in the Peri.B plasma were monitored after surgery in two patients with Peri.B plasma ctDNA (Figure 6B and 6C). The patient with adenocarcinoma was pathologically classified as T2aN0M1a at stage IV (Figure 6B). Platinum-based systemic chemotherapy was performed continuously; however, the ctDNA levels remained high after surgery, and the patient died on day 158 after the operation. The other patient had small cell carcinoma clinically classified as T2aN0M1a at stage IV (Figure 6C). Following surgery,

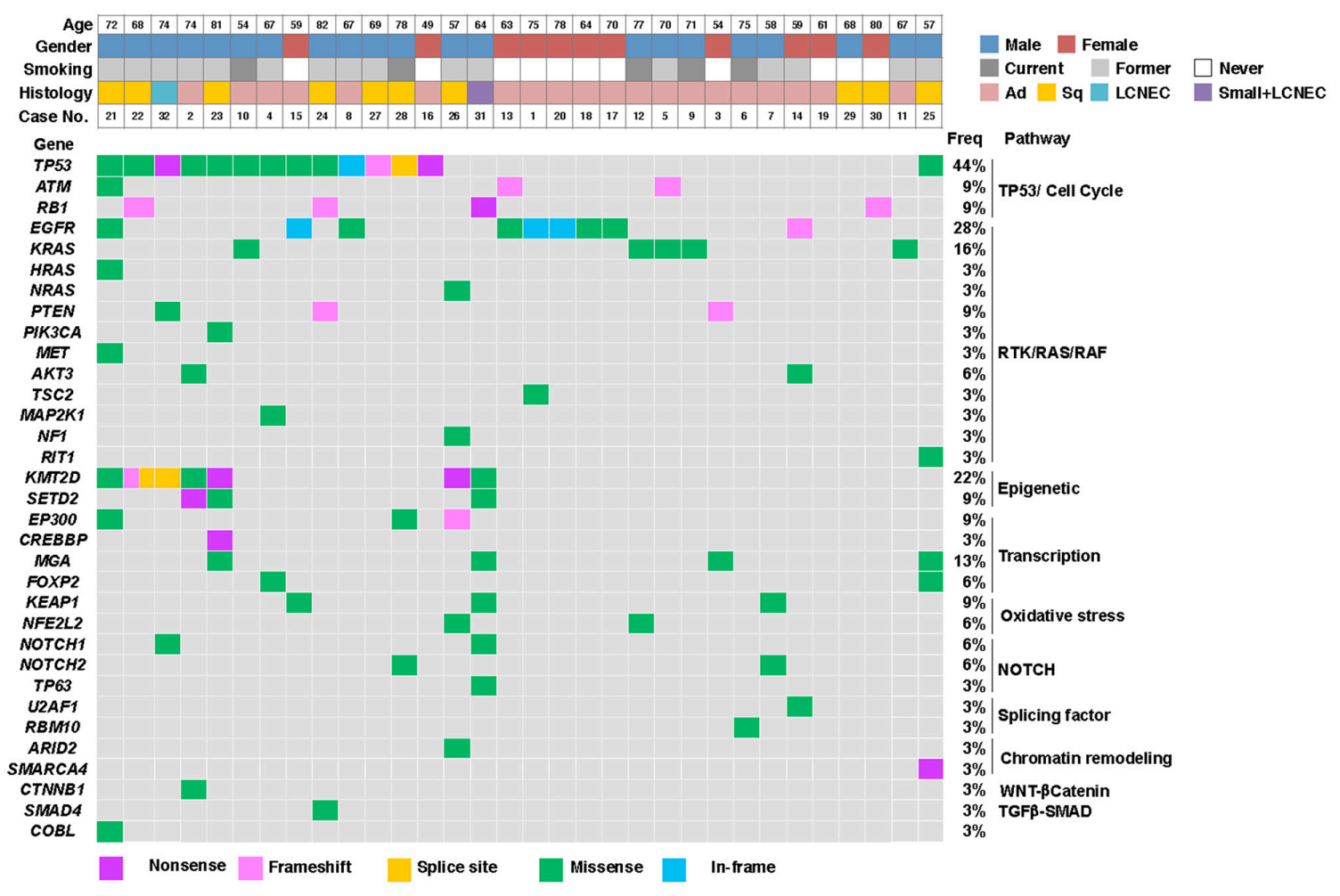

Figure 2: Lung cancer mutation profiles. Most cancers had more than one mutation and involved several different functional pathways. Case No. indicates the number of the corresponding case in Figure 1A. 
Table 1: Allele fractions of circulating tumor DNA detected in the samples

\begin{tabular}{|c|c|c|c|c|c|c|c|c|c|c|}
\hline Case & $\begin{array}{c}\text { Case No. in } \\
\text { Supplementary Table } 1\end{array}$ & Histology & Gene & $\begin{array}{l}\text { Primary } \\
\text { lesion }\end{array}$ & $\begin{array}{c}\text { Pul.V } \\
\text { Plasma }\end{array}$ & Pul.V Buffy & $\begin{array}{l}\text { Peri.B } \\
\text { Plasma }\end{array}$ & Peri.B Buffy & $\begin{array}{l}\text { BM. } \\
\text { sup }\end{array}$ & BM.ppt \\
\hline & & & TP53 & $85.0 \%$ & $37.0 \%$ & - & $19.0 \%$ & - & - & - \\
\hline & & & EGFR & $75.0 \%$ & $15.0 \%$ & - & $11.0 \%$ & - & - & - \\
\hline & & & HRAS & $59.0 \%$ & $19.0 \%$ & - & $7.0 \%$ & - & - & - \\
\hline & & & EP300 & $48.0 \%$ & $15.0 \%$ & - & $6.0 \%$ & - & - & - \\
\hline \multirow[t]{5}{*}{1} & 27 & $\mathrm{Sq}$ & COBL & $34.0 \%$ & - & - & - & - & - & - \\
\hline & & & ATM & $25.0 \%$ & - & - & - & - & - & - \\
\hline & & & EP300 & $25.0 \%$ & - & - & - & - & - & - \\
\hline & & & KMT2D & $22.0 \%$ & - & - & - & - & - & - \\
\hline & & & MET & $21.0 \%$ & - & - & - & - & - & - \\
\hline \multirow[t]{4}{*}{2} & 19 & Ad & KRAS & $97.0 \%$ & $76.0 \%$ & - & $55.0 \%$ & - & - & - \\
\hline & & & TP53 & $86.1 \%$ & $15.0 \%$ & - & $10.0 \%$ & - & - & - \\
\hline & & & SETD2 & $61.1 \%$ & - & - & - & - & - & - \\
\hline & & & TP53 & $53.1 \%$ & $2.3 \%$ & - & $0.4 \%$ & - & - & - \\
\hline \multirow[t]{7}{*}{3} & 21 & $\mathrm{Sq}$ & PIK3CA & $41.5 \%$ & $3.3 \%$ & - & - & - & - & - \\
\hline & & & MGA & $37.3 \%$ & $3.9 \%$ & - & - & - & - & - \\
\hline & & & CREBBP & $37.0 \%$ & $4.1 \%$ & - & - & - & - & - \\
\hline & & & KMT2D & $34.9 \%$ & $4.0 \%$ & - & - & - & - & - \\
\hline & & & KEAP1 & $93.8 \%$ & $3.7 \%$ & - & $1.9 \%$ & - & - & - \\
\hline & & & RB1 & $89.1 \%$ & $3.0 \%$ & - & - & - & - & - \\
\hline & & & MGA & $87.8 \%$ & $7.5 \%$ & - & $2.8 \%$ & - & - & - \\
\hline \multirow[t]{6}{*}{4} & 29 & Small & SETD2 & $78.5 \%$ & $1.6 \%$ & - & $1.0 \%$ & - & - & - \\
\hline & & & KMT2D & $32.1 \%$ & $2.0 \%$ & - & $0.8 \%$ & - & - & - \\
\hline & & & TP63 & $25.5 \%$ & $0.9 \%$ & - & - & - & - & - \\
\hline & & & NOTCH1 & $22.3 \%$ & - & - & - & - & - & - \\
\hline & & & NF1 & $50.3 \%$ & - & - & - & - & - & - \\
\hline & & & NRAS & $48.6 \%$ & - & - & - & - & - & - \\
\hline \multirow[t]{4}{*}{5} & 24 & $\mathrm{Sq}$ & ARID2 & $45.0 \%$ & - & - & - & - & - & - \\
\hline & & & NFE2L2 & $43.7 \%$ & $2.0 \%$ & - & - & - & - & - \\
\hline & & & EP300 & $40.9 \%$ & - & - & - & - & - & - \\
\hline & & & KMT2D & $29.1 \%$ & - & - & - & - & - & - \\
\hline
\end{tabular}

platinum-based systemic chemotherapy was performed. The ctDNA levels were undetectable after surgery and chemotherapy, and the patient is still alive without relapse, as of postoperative day 470 .

\section{DISCUSSION}

In this study, we found that the ctDNA frequency in the sampling sites, assuming that it was $100 \%$ in the primary tumor, was as follows: Pul.V plasma, 20\%; Peri.B plasma, 11\%; Pul.V pellet, $0 \%$; Peri.B pellet, $0 \%$; BM supernatant, $0 \%$; and $\mathrm{BM}$ pellet, $0 \%$. Furthermore, it was revealed that cancer-specific mutations were more frequent in Pul.V than in Peri.B plasma. Thus, a"spillover" of ctDNA into the immediate outflow tract (Pul.V) occurred; it was then diluted, but still present, in the returning circulation (Peri.B). ctDNA has been reported to have a short half-life (2 h) [23]; once it is spilled out of cancer cells, it disseminates and disappears rapidly. Consequently, it was assumed that ctDNA levels decreased below the detectable level in BM fluid and other body fluids in regions distant from tumors. The AF of the ctDNA correlated with that of the DNA detected in the primary lesion, suggesting that ctDNA might accurately 
reflect predominant mutations that arise in the primary lesion.

Individual lung cancers could harbor more than one mutation, contributing to intratumor heterogeneity $[2-4,36]$. In the current study, the number of mutations was larger in SCCs than in adenocarcinomas, and larger in smokers than in non-smokers; these results were consistent with previously reported findings [37-39]. In SCCs and in smokers with lung cancer, it is assumed that the cancer is poorly differentiated because of the accumulation of a higher number of mutations than in non-SCCs and non-smokers, respectively. There have been reports of lower survival rates in SCCs than adenocarcinomas, even at the same disease stage [40, 41].

In clinical practice, there are no standard methods for determining the driver mutation among the several mutations found in lung cancer. In the current study, as described in many reports, we considered mutations with higher AF more likely to be driver mutations. Our data indicated that individual lung cancers harbor 2.7 significant mutations on average; selecting the mutation to be target for treatment among these will be a major issue for medical treatment in the future.
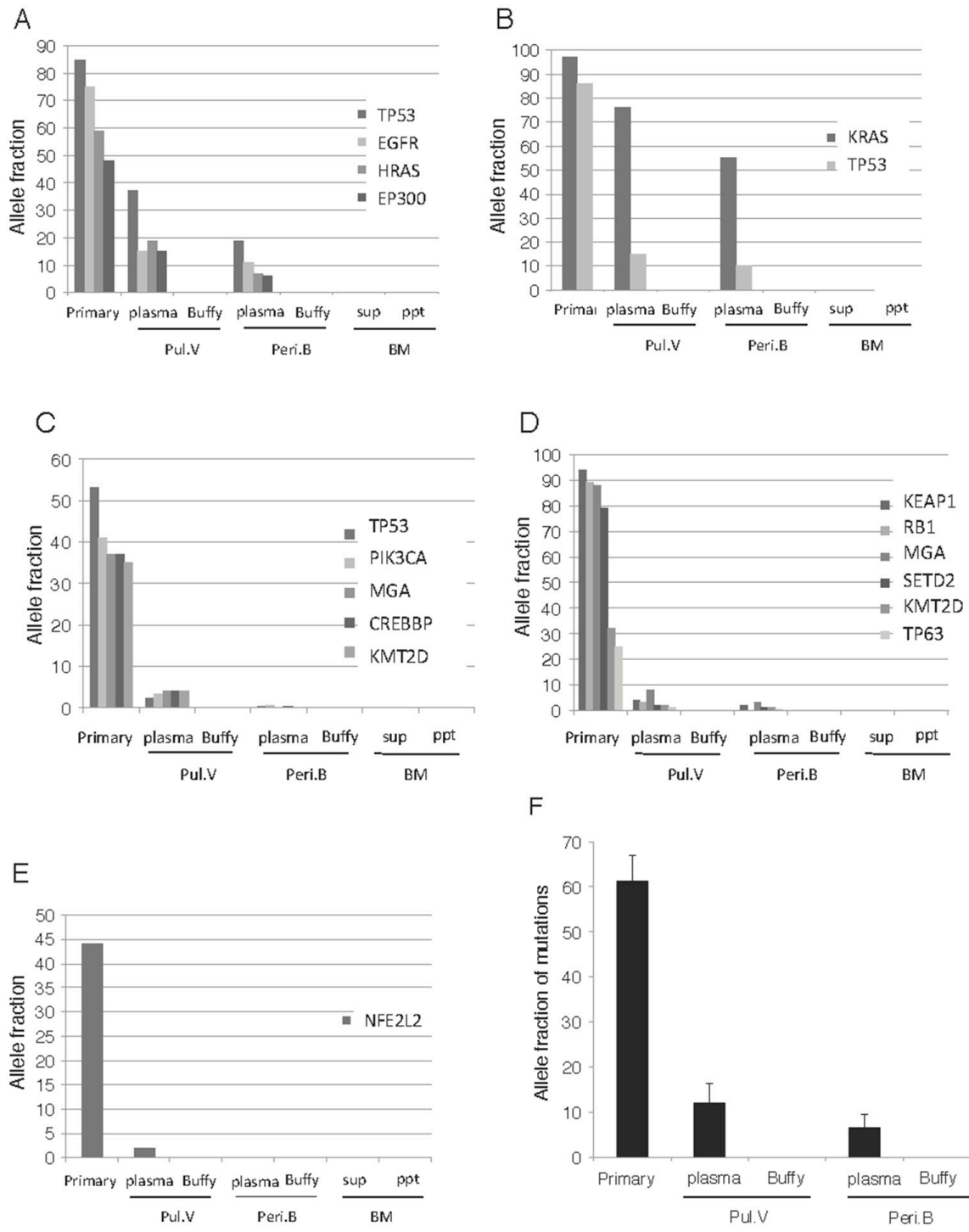

F

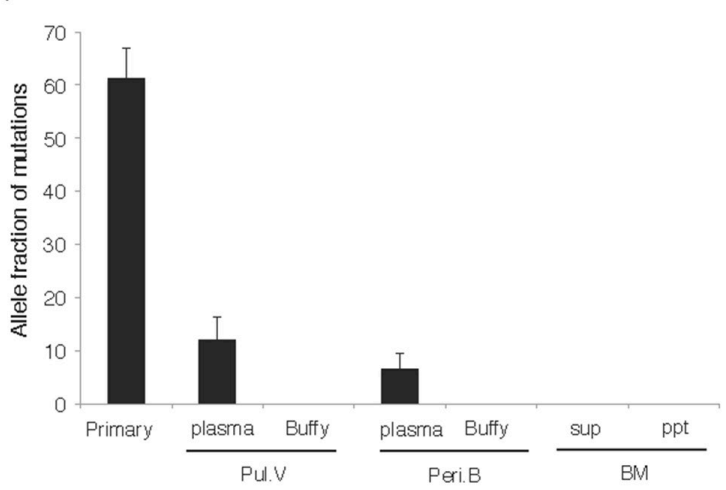

Figure 3: Analysis of the ctDNA distribution pattern. (A-E) In 5 of the 30 patients, ctDNA was detected in the Pul.V and Peri.B plasma. Tumor DNA was not detected in the cell fractions or BM fluid, but was detected in three types of samples; the primary lesion, Pul.V plasma, and Peri.B plasma. Among these three samples, the gradients of AF for each mutation were always concordant, as follows. Primary lesion $>$ Pul.V plasma $>$ Peri.B plasma. Panels A-E correspond to Cases 1-5 in Table 1. (F) Compiling the data of these 5 patients, the allele fraction in the primary lesion was found to be significantly higher than that in the other 6 specimens. $※, p<0.05$. Assuming the primary tumor to be $100 \%$, the frequencies of the mutations were as follows: Pul.V plasma, 20\%; Peri.B plasma, $11 \%$; Pul.V pellet, $0 \%$; Peri.B pellet, $0 \%$; supernatant of $\mathrm{BM}, 0 \%$; and pellet of $\mathrm{BM}, 0 \%$. 
Table 2: The number of mutations in the cancers with or without circulating tumor DNA release

\begin{tabular}{lccc}
\hline & ctDNA(-) & ctDNA(+) & $p$ value \\
\hline AF $>1 \%$ & $(\mathbf{n}=\mathbf{2 7})$ & $(\mathbf{n}=\mathbf{5})$ & $<0.05$ \\
$\mathrm{AF}>20 \%$ & $7.8 \pm 3.6$ & $28.7 \pm 8.1$ & $<0.05$ \\
\hline
\end{tabular}

The RAS and TP53 pathways have been reported to be the major pathways involved in lung cancer [24, 37]; our results were consistent with these reports. Adenocarcinomas with EGFR mutations is prevalent among Asians [38, 42]. The current study revealed that whereas the RAS pathway was affected mainly in adenocarcinomas, the TP53 pathway was affected mostly
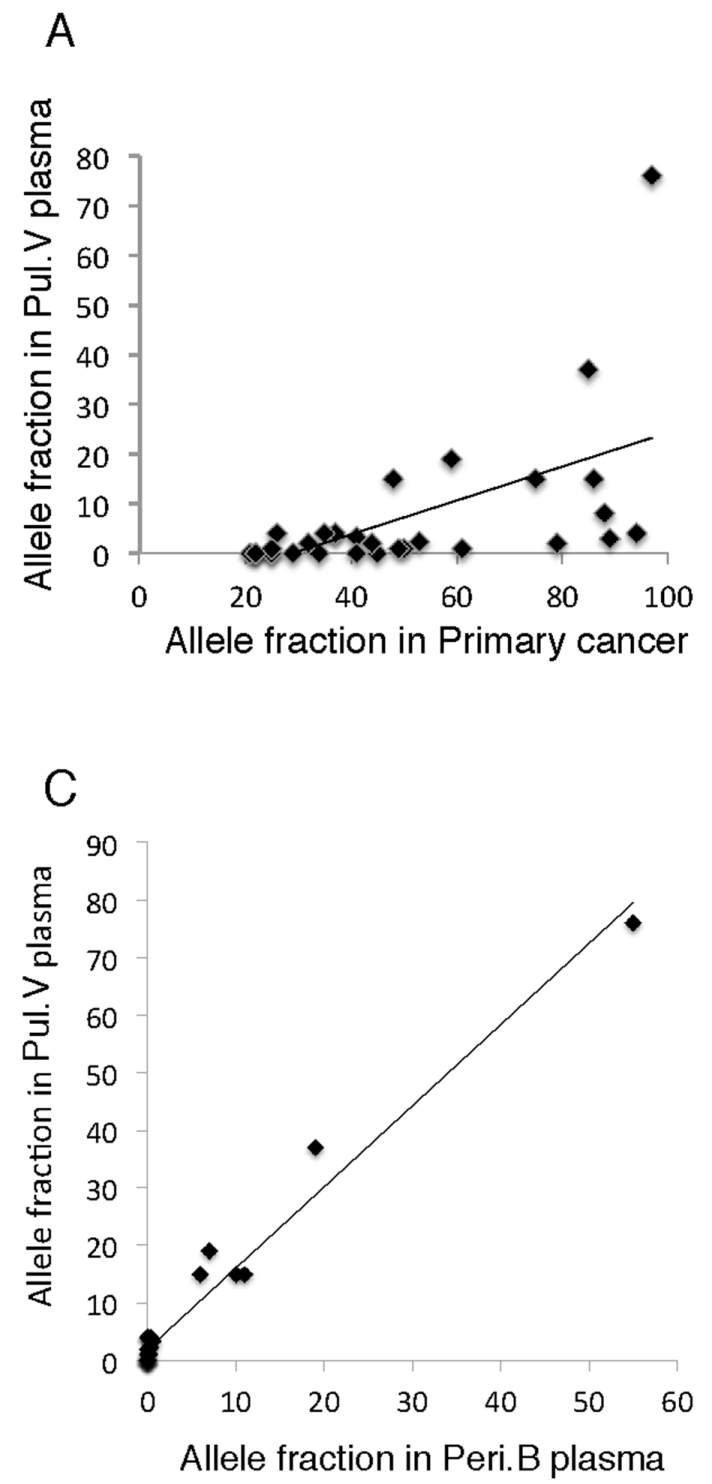

in patients with SCCs, as reported in many studies [2, 37]. Generally, pathways such as those for chromatin remodeling, epigenetics, and transcription are thought to be relatively minor pathways in lung cancer; however, in SCCs, smoking presumably triggers the accumulation of mutations in such pathways through a progressive or evolutionary process, which results in conversion to a

\section{B}

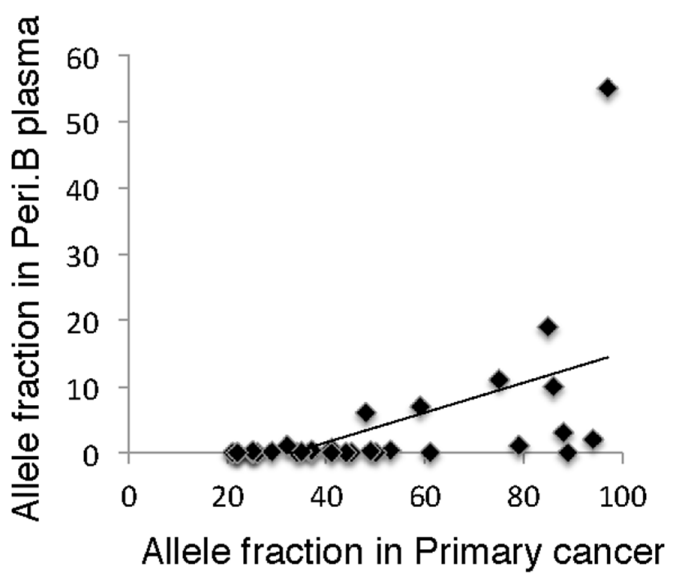

Figure 4: Correlation between allele fractions of the mutated genes in different samples. (A-B) AF of the mutations detected in the primary lesion correlated significantly with that of mutations in the ctDNAs detected in Pul.V and Peri.B plasma $(\mathrm{R}=0.57, p<0.05$ and $\mathrm{R}=0.54, p<0.05$, respectively). (C) There was a clear correlation between the AFs of mutations in the ctDNA detected in Pul.V and Peri.B plasma $(\mathrm{R}=0.98, p<0.05)$. 
Table 3: Clinical and pathological characteristics of patients with or without detected circulating tumor DNA

\begin{tabular}{|c|c|c|c|}
\hline & $\operatorname{ctDNA}(-)$ & $\operatorname{ctDNA}(+)$ & $p$ value \\
\hline Number of patients & 25 & 5 & - \\
\hline Male/Female & $14 / 11$ & $5 / 0$ & $<0.05$ \\
\hline Age & $68.4 \pm 1.8$ & $65.6 \pm 4.0$ & NS \\
\hline \multicolumn{4}{|l|}{ Smoking habit } \\
\hline smoker/non-smoker & $15 / 10$ & $5 / 0$ & $<0.05$ \\
\hline Tumor size (mm) & $30.8 \pm 4.7$ & $64.0 \pm 10.6$ & $<0.05$ \\
\hline \multicolumn{4}{|l|}{ Surgical curativity } \\
\hline curative/non-curative & $23 / 2$ & $3 / 2$ & 0.09 \\
\hline \multicolumn{4}{|l|}{ Histology } \\
\hline $\mathrm{Ad} / \mathrm{Sq} /$ others & $18 / 6 / 1$ & $1 / 3 / 1$ & $<0.05$ \\
\hline \multicolumn{4}{|l|}{ Pathological stage } \\
\hline I/II/III/IV & $17 / 3 / 3 / 2$ & $1 / 1 / 1 / 2$ & 0.08 \\
\hline \multicolumn{4}{|l|}{ Pathological vessel invasion } \\
\hline present/absent & $9 / 16$ & $3 / 2$ & NS \\
\hline \multicolumn{4}{|c|}{ Pathological lymphatic invasion } \\
\hline present/absent & $7 / 18$ & $1 / 4$ & NS \\
\hline \multicolumn{4}{|l|}{ Adjuvant chemotherapy } \\
\hline performed/ not performed & $7 / 18$ & $3 / 2$ & NS \\
\hline
\end{tabular}

Ad: adenocarcinoma, Sq: squamous cell carcinoma, NS: not significant.

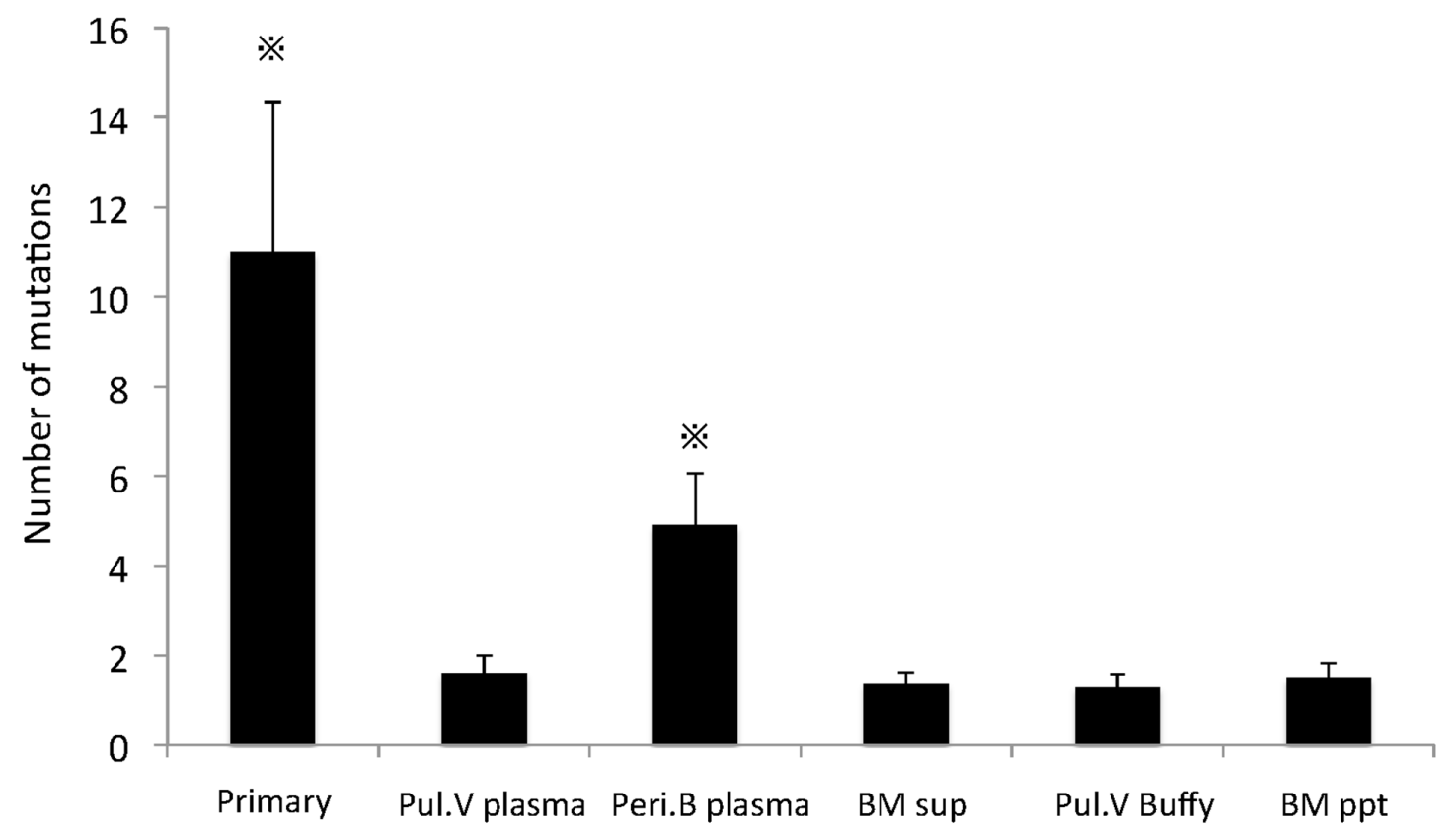

Figure 5: Number of mutations in the specimens, including lung cancer-nonspecific ones. The number of mutations in the primary lesion and Peri.B plasma was significantly larger than that in the other 4 specimens. $※, p<0.05$. In this analysis, the number of mutations in Peri.B Buffy was set at 0, because these leukocytes were utilized as the normal controls. 
poorly differentiated phenotype. In fact, the tumors in none of the 30 patients in the current study exclusively harbored mutations of only one of these three pathways. It is assumed that SCCs arise and progress through the coordinated effects of these and other mutated pathways.

In five of the 30 patients with lung cancer, ctDNA was detected in plasma at a low detection rate $(16.7 \%)$. In this study, peripheral blood was drawn before surgery, while pulmonary venous blood was drawn after surgery. Therefore, it is possible that the surgery itself caused ctDNA to be released into the blood. Despite this possibility, the strong correlations between the mutations in the pulmonary venous and peripheral blood, as shown in Figure 4C, suggested that they were derived from the same mechanism of release. From the clinical perspective, it is important to determine ctDNA-positive cases. The current study, which included 30 surgical patients selected in an unbiased fashion, is unique in that patients with various histological types at different disease stages were included. The clinical features associated with ctDNA detection were large cancer size, advanced stage, and SCC histology. In this context, tumor burden and tumor cell proliferation rates might have a substantial role in the physiology and rate of ctDNA release. In addition, we also analyzed the mutational profiles of ctDNA-positive cases. As shown in Table 2 and Supplementary Figure 2, ctDNA was detected more frequently in patients with cancers that harbored many mutations and/or cancers that harbored mutations of the epigenetic or transcription pathways. This should be interpreted as a consequence of ctDNA release from SCCs and/or large lung cancers.

In the current study, Pul.V, Peri.B, and BM fluid samples were used to perform deep sequencing on both cell and supernatant fractions. There are two accessible sources of tumor DNA in the blood: CTCs and ctDNA $[43,44]$. Although a simple comparison of the two sources is difficult because of the differences in the detection methods used, the current study detected no mutated genes in the cell fractions, even in patients positive for ctDNA. It was evident that ctDNA was more readily detectable than CTCs. Many recent studies have reported that ctDNA levels were higher than the CTC levels [15, $45,46]$, and our results were consistent with these reports. Furthermore, we had previously reported that ctDNA in plasma was a more sensitive and clinically useful biomarker than DNA in the BM fluid [47].
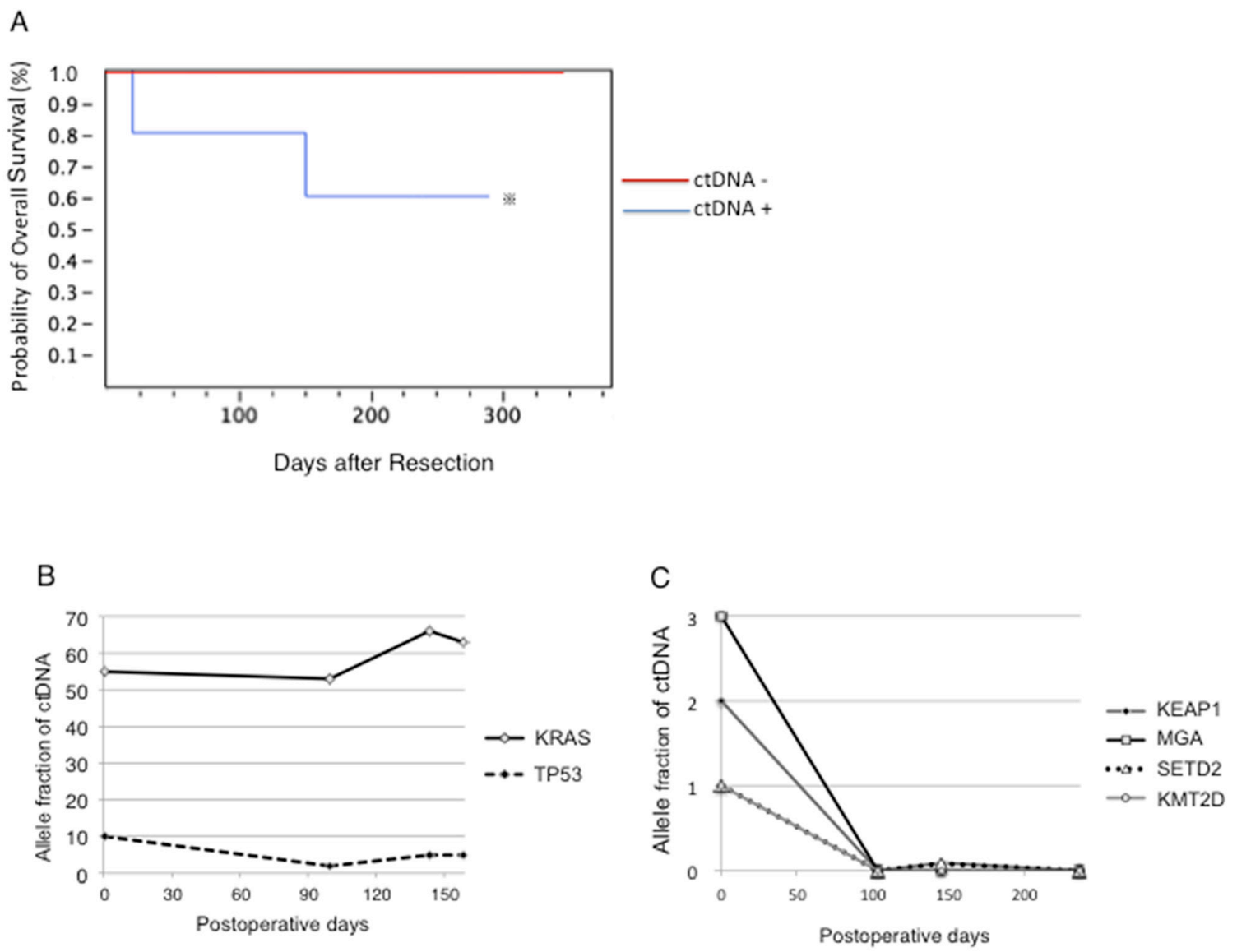

Figure 6: Clinical outcomes of the presence of ctDNA in the plasma. (A) Five patients with plasma ctDNA exhibited significantly poorer survival than the 25 patients without ctDNA in their plasma. $※, p<0.05$. (B-C) Changes in ctDNA after surgery reflects cancer progression and predicts the outcome. Panels B and C represent Cases 2 and 4, respectively, in Table 1. 
As shown in Figure 6A, there was a marked correlation between ctDNA and poor survival rate, suggesting that detecting ctDNA with targeted deep sequencing could provide useful prognostic information on patients after surgery. Furthermore, the two patients who died had the highest AF of ctDNA in the peripheral blood, while another three patients with AF in peripheral blood $<3 \%$ survived without recurrence, indicating that ctDNA-positivity and AF might be associated with poor survival.

ctDNA also showed a more dynamic range that correlated with changes in the tumor burden, as shown in Figure 6B. We demonstrated that noninvasively tracking mutations in plasma DNA could help detect residual diseases that standard surgery failed to eradicate, and thus identify patients with high risk of recurrence. In the current study, cancer-specific mutations were detected more frequently in Pul.V plasma, and the AF of ctDNA in the Pul.V plasma was approximately twice that in the Peri.B plasma. In fact, a number of mutated ctDNA fragments were detected only in the Pul.V plasma. Thus, collecting Pul.V blood from surgical samples instead of the conventional Peri.B sampling could further facilitate the detection of ctDNA, and consequently, enable a more accurate assessment of disease progression. However, ctDNA have not been confirmed to act as reliable markers of cancer progression. Our findings need to be validated by larger and comparative studies in the future.

Our chosen approach for collecting pulmonary venous blood could potentially be used in interventional radiology. In patients with lung cancer, pulmonary venous blood samples could be collected with a catheter for clinical use. Our results indicated that the ctDNA released from lung cancer into the pulmonary venous blood was more lung cancer-specific, abundant, and precise than the ctDNA in the peripheral blood. Thus, pulmonary venous blood appeared to be a better source of ctDNA than peripheral blood, in terms of both sensitivity and specificity. In the future, measuring ctDNA in the Pul.V plasma might be useful for monitoring tumor dynamics, detecting minimal residual diseases, detecting resistant mutations, and other diagnostic/prognostic procedures.

It has been reported that a higher burden of nonsynonymous mutations in tumors is associated with clinical benefits of immune checkpoint therapy [48]. As shown in the current study, ctDNA is more likely to be released in lung cancers with a higher mutation burden; thus, measuring the amount of ctDNA might provide pivotal information during the course of immune checkpoint therapy. Although we showed that the liquid biopsy approach is promising, its clinical utility has not been evaluated in a cohort study. Our results could lead to various such cohort studies, including those of adjuvant chemotherapy after lung cancer surgery.

One limitation of the current study that should be considered is the small sample size. Nevertheless, the results have translational implications and suggest important avenues for future research.

We expect that ctDNA will be increasingly used as a tumor progression marker for assessing the therapeutic effects of anticancer agents and other processes in clinical practice. Evolutionary changes that take place within cancers could affect both the mutational spectrum of the disease and its sensitivity to treatment [22, 49-54]. We envision a time when blood-based gene profiling supplements tumor genotyping to track the heterogeneous and evolving genomic landscape, thus informing treatment strategies and realizing safer and more precise strategies for cancer management.

In conclusion, we showed that, in the natural course of the disease, ctDNA spills directly out of tumors into the pulmonary venous blood and is then disseminated to the entire body. As ctDNA reflects the predominant mutations in the primary lesion and bears promise as a prognostic marker that closely reflects disease progression, its measurement might be used in the future as a "liquid biopsy" in the real sense.

\section{MATERIALS AND METHODS}

\section{Patients and sample preparation}

We selected the first 30 patients with lung cancer admitted to our hospital between September 2014 and February 2015. Before surgery, we explained the surgical procedures to each patient, including the rib resection and sample collection from the lung, blood, and bone marrow. All the patients provided written informed consent for these procedures as well as for the genetic research, which was performed in accordance with protocols approved by the Institutional Review Board of our hospital.

A peripheral blood sample was drawn from the patients just prior to surgery. According to our policy, standard resection of lung cancer (i.e., lobectomy) was performed with an open-chest approach. Immediately after the lobectomy, the pulmonary vein was punctured in order to collect the pulmonary venous blood. Blood samples were collected in EDTA-2Na tubes. During surgery, specimens (approximately $1 \mathrm{~cm}$ in length) were collected by dissecting the $5^{\text {th }}$ and $6^{\text {th }}$ ribs. Immediately after rib resection, the bone marrow space in the rib was repeatedly washed until all the components were removed and the bone marrow cell suspensions thus were obtained. After collecting the blood and bone marrow samples, they were immediately sent to the genome analysis center of our hospital. Centrifugation was initiated within $1 \mathrm{~h}$ of acquisition of each sample. The buffy coat (pulmonary venous blood and peripheral blood) and cell pellets (rib bone marrow fluid) were isolated after centrifugation of these samples at $820 \times \mathrm{g}$ for $10 \mathrm{~min}$ at $25^{\circ} \mathrm{C}$. Plasma from the blood and supernatant of the bone marrow fluid was centrifuged at $20,000 \times g$ for $10 \mathrm{~min}$ and the 
supernatant was subsequently transferred to sterile tubes and stored at $-80^{\circ} \mathrm{C}$ before DNA extraction. Total DNA was extracted from lymphocytes and cell pellets using the QIAamp DNA Blood Mini Kit (Qiagen, Tokyo, Japan), and DNA was purified from the plasma and supernatant using the QIAamp Circulating Nucleic Acid Kit (Qiagen). Serial sections of formalin-fixed, paraffin-embedded (FFPE) tissue were stained with hematoxylin-eosin and microdissected using an ArcturusXT laser-capture microdissection system (Thermo Fisher Scientific, Tokyo, Japan). Tumor DNA was extracted using the QIAamp DNA FFPE Tissue Kit (Qiagen).

\section{Assessment of DNA integrity with quantitative real time PCR}

DNA fragmentation in the FFPE DNA was assessed using the TaqMan RNase P Detection Reagents Kit and the FFPE DNA QC Assay on a ViiA7 Real-Time PCR instrument (Thermo Fisher Scientific). Human control genomic DNA (included in the TaqMan RNase P Detection Reagents Kit) was serially diluted 4 times for a 5-point standard curve and the absolute DNA concentrations were determined. Assessment of DNA fragmentation was estimated with the ratio of the DNA (relative quantification, RQ) obtained for the long amplicon (256 bp) to the short amplicon ( $87 \mathrm{bp}$ ). The RQ value was used as an indicator of the degradation level of genomic DNA.

\section{Targeted deep sequencing and data analysis}

A panel targeting the exons of 53 lung cancerassociated genes was established to perform targeted sequencing, as described in our previous study [47]. The genes were selected based on our literature review and the following criteria (Supplementary Table 4): (a) genes often involved in lung cancer, obtained from TCGA [2, 3] and other projects [55-59] and (b) genes frequently mutated in lung cancer, obtained from the COSMIC database (http://cancer.sanger.ac.uk/cancergenome/ projects/cosmic). The primers for the targeted sequencing were designed using the Ion AmpliSeq designer software (Thermo Fisher Scientific), as reported in a previous study $[60,61]$. Sequencing libraries were prepared using the Ion AmpliSeq Library kit (Thermo Fisher Scientific), according to the manufacturer's instructions. After barcode ligation using the Ion Xpress Barcode Adapters kit (Thermo Fisher Scientific), library samples were purified using the Agencourt AMPure XP reagent (Beckman Coulter, Tokyo, Japan) and then quantified using the Ion Library Quantitation Kit (Thermo Fisher Scientific). The libraries were templated with the Ion PI Template OT2 200 Kit v3 (Thermo Fisher Scientific). Sequencing was carried out on an Ion Proton (Ion Torrent, Thermo Fisher Scientific) using the Ion PI Sequencing 200 Kit v3. The sequence data were processed using the standard Ion Torrent Suite
Software running on the Torrent Server. Raw signal data were analyzed using Torrent Suite version 4.0. The pipeline included signaling, processing, base calling, quality score assignment, and read alignment with the human genome 19 reference (hg19), along with quality control of mapping and coverage analysis. After data analysis, the single nucleotide variants, insertions, and deletions were annotated using the Ion Reporter Server System (Thermo Fisher Scientific); lymphocytes from peripheral blood DNA were used as controls to detect variants (Tumor-Normal pair analysis). The average sequencing coverage depth and uniformity were 593-fold and 83\%, respectively (Supplementary Table 5). To detect somatic mutations in tumors with confidence, mutations with a variant allele fraction $\geq 20 \%$ were used. These somatic mutations were sought in the blood and bone marrow as well, and sequence data were visually confirmed using the Integrative Genomics Viewer.

\section{Statistical analysis}

Continuous variables were presented as the mean \pm SE and compared using the unpaired Student's $t$-test. Oneway analysis of variance and Tukey-Krammer multiple comparisons tests were used to detect statistical significance between groups. Chi-square tests were used to compare the categorical data between groups. Multivariate analyses were performed to identify factors that affected the release of ctDNA. Correlation between samples was calculated using the Pearson's correlation coefficient. Overall survival time was defined as the period from the day of operation to the day of death or the day of the last follow-up evaluation. Survival was assessed using the Kaplan-Meier method, and comparisons among the survival curves were performed using the log-rank test. All statistical analyses were performed using the JMP function in the SAS software package (SAS Institute, Inc., Cary, NC). $P$ values less than 0.05 in two-tailed analyses were considered to denote statistical significance.

\section{Abbreviations}

ctDNA: circulating tumor DNA; BM: bone marrow; Pul.V: pulmonary venous blood; Peri.B: peripheral blood; SCC: squamous cell carcinoma; CTC: circulating tumor cell; AF: allele fraction; FFPE: formalin fixed, paraffin embedded.

\section{Author contributions}

TG and YH contributed equally to this work.

TG and YH co-wrote the manuscript. TG, TN, DS, and YY performed the surgery. TO performed the pathological examination. YH, KA, TG, TN, YY, KO, $\mathrm{HM}$, and MO performed the genomic analyses. $\mathrm{MO}$ and $\mathrm{YH}$ were involved in the final editing. All authors have read and approved the final manuscript. 


\section{ACKNOWLEDGMENTS}

The authors acknowledge Takuro Uchida, Hidetoshi Shigetomo, and Yumi Kubota for helpful scientific discussions.

\section{CONFLICTS OF INTEREST}

The authors declare no conflicts of interest.

\section{FUNDING}

This study was supported by a Grant-in-Aid for Genome Research Project from Yamanashi Prefecture (YH and MO) and a grant from The YASUDA Medical Foundation (YH).

\section{REFERENCES}

1. Vogelstein B, Papadopoulos N, Velculescu VE, Zhou S, Diaz LA Jr, Kinzler KW. Cancer genome landscapes. Science. 2013; 339:1546-1558.

2. Cancer Genome Atlas Research Network. Comprehensive genomic characterization of squamous cell lung cancers. Nature. 2012; 489:519-525.

3. Cancer Genome Atlas Research Network. Comprehensive molecular profiling of lung adenocarcinoma. Nature. 2014; 511:543-550.

4. George J, Lim JS, Jang SJ, Cun Y, Ozretic L, Kong G, Leenders F, Lu X, Fernandez-Cuesta L, Bosco G, Muller C, Dahmen I, Jahchan NS, et al. Comprehensive genomic profiles of small cell lung cancer. Nature. 2015; 524:47-53.

5. Mardis ER. Genome sequencing and cancer. Curr Opin Genet Dev. 2012; 22:245-250.

6. Meyerson M, Gabriel S, Getz G. Advances in understanding cancer genomes through second-generation sequencing. Nat Rev Genet. 2010; 11:685-696.

7. Stratton MR. Exploring the genomes of cancer cells: progress and promise. Science. 2011; 331:1553-1558.

8. Yates LR, Campbell PJ. Evolution of the cancer genome. Nat Rev Genet. 2012; 13:795-806.

9. Board RE, Wardley AM, Dixon JM, Armstrong AC, Howell S, Renshaw L, Donald E, Greystoke A, Ranson M, Hughes A, Dive C. Detection of PIK3CA mutations in circulating free DNA in patients with breast cancer. Breast Cancer Res Treat. 2010; 120:461-467.

10. Schwarzenbach H, Hoon DS, Pantel K. Cell-free nucleic acids as biomarkers in cancer patients. Nat Rev Cancer. 2011; 11:426-437.

11. Ballehaninna UK, Chamberlain RS. Serum CA 19-9 as a biomarker for pancreatic cancer-a comprehensive review. Indian J Surg Oncol. 2011; 2:88-100.

12. Mazzucchelli R, Colanzi P, Pomante R, Muzzonigro G, Montironi R. Prostate tissue and serum markers. Adv Clin Path. 2000; 4:111-120.
13. Sikaris KA. CA125--a test with a change of heart. Heart Lung Circ. 2011; 20:634-640.

14. Stroun M, Lyautey J, Lederrey C, Olson-Sand A, Anker P. About the possible origin and mechanism of circulating DNA apoptosis and active DNA release. Clin Chim Acta. 2001; 313:139-142.

15. Bettegowda C, Sausen M, Leary RJ, Kinde I, Wang Y, Agrawal N, Bartlett BR, Wang H, Luber B, Alani RM, Antonarakis ES, Azad NS, Bardelli A, et al. Detection of circulating tumor DNA in early- and late-stage human malignancies. Sci Transl Med. 2014; 6:224ra224.

16. Forshew T, Murtaza M, Parkinson C, Gale D, Tsui DW, Kaper F, Dawson SJ, Piskorz AM, Jimenez-Linan M, Bentley D, Hadfield J, May AP, Caldas C, et al. Noninvasive identification and monitoring of cancer mutations by targeted deep sequencing of plasma DNA. Sci Transl Med. 2012; 4:136ra168.

17. Leon SA, Shapiro B, Sklaroff DM, Yaros MJ. Free DNA in the serum of cancer patients and the effect of therapy. Cancer Res. 1977; 37:646-650.

18. Bordi P, Del Re M, Danesi R, Tiseo M. Circulating DNA in diagnosis and monitoring EGFR gene mutations in advanced non-small cell lung cancer. Transl Lung Cancer Res. 2015; 4:584-597.

19. Gray ES, Rizos H, Reid AL, Boyd SC, Pereira MR, Lo J, Tembe V, Freeman J, Lee JH, Scolyer RA, Siew K, Lomma C, Cooper A, et al. Circulating tumor DNA to monitor treatment response and detect acquired resistance in patients with metastatic melanoma. Oncotarget. 2015; 6:4200842018. https://doi.org/10.18632/oncotarget.5788.

20. Tjensvoll K, Lapin M, Buhl T, Oltedal S, Steen-Ottosen Berry K, Gilje B, Soreide JA, Javle M, Nordgard O, Smaaland R. Clinical relevance of circulating KRAS mutated DNA in plasma from patients with advanced pancreatic cancer. Mol Oncol. 2016; 10:635-643.

21. Xu S, Lou F, Wu Y, Sun DQ, Zhang JB, Chen W, Ye H, Liu JH, Wei S, Zhao MY, Wu WJ, Su XX, Shi R, Jones L, et al. Circulating tumor DNA identified by targeted sequencing in advanced-stage non-small cell lung cancer patients. Cancer Lett. 2016; 370:324-331.

22. Diaz LA Jr, Williams RT, Wu J, Kinde I, Hecht JR, Berlin J, Allen B, Bozic I, Reiter JG, Nowak MA, Kinzler KW, Oliner KS, Vogelstein B. The molecular evolution of acquired resistance to targeted EGFR blockade in colorectal cancers. Nature. 2012; 486:537-540.

23. Diehl F, Schmidt K, Choti MA, Romans K, Goodman S, Li M, Thornton K, Agrawal N, Sokoll L, Szabo SA, Kinzler KW, Vogelstein B, Diaz LA Jr. Circulating mutant DNA to assess tumor dynamics. Nat Med. 2008; 14:985-990.

24. Crowley E, Di Nicolantonio F, Loupakis F, Bardelli A. Liquid biopsy: monitoring cancer-genetics in the blood. Nat Rev Clin Oncol. 2013; 10:472-484.

25. Leary RJ, Kinde I, Diehl F, Schmidt K, Clouser C, Duncan C, Antipova A, Lee C, McKernan K, De La Vega 
FM, Kinzler KW, Vogelstein B, et al. Development of personalized tumor biomarkers using massively parallel sequencing. Sci Transl Med. 2010; 2:20ra14.

26. McBride DJ, Orpana AK, Sotiriou C, Joensuu H, Stephens PJ, Mudie LJ, Hamalainen E, Stebbings LA, Andersson LC, Flanagan AM, Durbecq V, Ignatiadis M, et al. Use of cancer-specific genomic rearrangements to quantify disease burden in plasma from patients with solid tumors. Genes Chromosomes Cancer. 2010; 49:1062-1069.

27. Murtaza M, Dawson SJ, Tsui DW, Gale D, Forshew T, Piskorz AM, Parkinson C, Chin SF, Kingsbury Z, Wong AS, Marass F, Humphray S, Hadfield J, et al. Non-invasive analysis of acquired resistance to cancer therapy by sequencing of plasma DNA. Nature. 2013; 497:108-112.

28. Sacher AG, Paweletz C, Dahlberg SE, Alden RS, O'Connell A, Feeney N, Mach SL, Janne PA, Oxnard GR. Prospective validation of rapid plasma genotyping for the detection of EGFR and KRAS mutations in advanced lung cancer. JAMA Oncol. 2016; 2:1014-22.

29. Hou JM, Krebs M, Ward T, Sloane R, Priest L, Hughes A, Clack G, Ranson M, Blackhall F, Dive C. Circulating tumor cells as a window on metastasis biology in lung cancer. Am J Pathol. 2011; 178:989-996.

30. Hou JM, Krebs MG, Lancashire L, Sloane R, Backen A, Swain RK, Priest LJ, Greystoke A, Zhou C, Morris K, Ward T, Blackhall FH, Dive C. Clinical significance and molecular characteristics of circulating tumor cells and circulating tumor microemboli in patients with small-cell lung cancer. J Clin Oncol. 2012; 30:525-532.

31. Krebs MG, Sloane R, Priest L, Lancashire L, Hou JM, Greystoke A, Ward TH, Ferraldeschi R, Hughes A, Clack G, Ranson M, Dive C, Blackhall FH. Evaluation and prognostic significance of circulating tumor cells in patients with non-small-cell lung cancer. J Clin Oncol. 2011; 29:1556-1563.

32. Pailler E, Adam J, Barthelemy A, Oulhen M, Auger N, Valent A, Borget I, Planchard D, Taylor M, Andre F, Soria JC, Vielh P, Besse B, Farace F. Detection of circulating tumor cells harboring a unique ALK rearrangement in ALKpositive non-small-cell lung cancer. J Clin Oncol. 2013; 31:2273-2281.

33. Pantel K, Brakenhoff RH, Brandt B. Detection, clinical relevance and specific biological properties of disseminating tumour cells. Nat Rev Cancer. 2008; 8:329-340.

34. Riethdorf S, Wikman H, Pantel K. Review: biological relevance of disseminated tumor cells in cancer patients. Int J Cancer. 2008; 123:1991-2006.

35. Rud AK, Borgen E, Maelandsmo GM, Flatmark K, Le H, Josefsen D, Solvoll I, Schirmer CB, Helland A, Jorgensen L, Brustugun OT, Fodstad O, Boye K. Clinical significance of disseminated tumour cells in non-small cell lung cancer. Br J Cancer. 2013; 109:1264-1270.

36. Zhang J, Fujimoto J, Zhang J, Wedge DC, Song X, Zhang J, Seth S, Chow CW, Cao Y, Gumbs C, Gold KA, Kalhor
$\mathrm{N}$, Little L, et al. Intratumor heterogeneity in localized lung adenocarcinomas delineated by multiregion sequencing. Science. 2014; 346:256-259.

37. Gibbons DL, Byers LA, Kurie JM. Smoking, p53 mutation, and lung cancer. Mol Cancer Res. 2014; 12:3-13.

38. Gou LY, Niu FY, Wu YL, Zhong WZ. Differences in driver genes between smoking-related and non-smoking-related lung cancer in the Chinese population. Cancer. 2015; 121:3069-3079.

39. Schumacher TN, Schreiber RD. Neoantigens in cancer immunotherapy. Science. 2015; 348:69-74.

40. Kawase A, Yoshida J, Ishii G, Nakao M, Aokage K, Hishida T, Nishimura M, Nagai K. Differences between squamous cell carcinoma and adenocarcinoma of the lung: are adenocarcinoma and squamous cell carcinoma prognostically equal? Jpn J Clin Oncol. 2012; 42:189-195.

41. Kinoshita T, Ohtsuka T, Yotsukura M, Asakura K, Goto T, Kamiyama I, Otake S, Tajima A, Emoto K, Hayashi Y, Kohno M. Prognostic impact of preoperative tumor marker levels and lymphovascular invasion in pathological stage I adenocarcinoma and squamous cell carcinoma of the lung. J Thorac Oncol. 2015; 10:619-628.

42. Kohno T, Tsuta K, Tsuchihara K, Nakaoku T, Yoh K, Goto K. RET fusion gene: translation to personalized lung cancer therapy. Cancer Sci. 2013; 104:1396-1400.

43. Alix-Panabieres C, Schwarzenbach H, Pantel K. Circulating tumor cells and circulating tumor DNA. Annu Rev Med. 2012; 63:199-215.

44. Fleischhacker M, Schmidt B. Circulating nucleic acids (CNAs) and cancer--a survey. Biochim Biophys Acta. 2007; 1775:181-232.

45. Sausen M, Leary RJ, Jones S, Wu J, Reynolds CP, Liu X, Blackford A, Parmigiani G, Diaz LA Jr, Papadopoulos N, Vogelstein B, Kinzler KW, Velculescu VE, Hogarty MD. Integrated genomic analyses identify ARID1A and ARID1B alterations in the childhood cancer neuroblastoma. Nat Genet. 2013; 45:12-17.

46. Dawson SJ, Tsui DW, Murtaza M, Biggs H, Rueda OM, Chin SF, Dunning MJ, Gale D, Forshew T, Mahler-Araujo B, Rajan S, Humphray S, Becq J, et al. Analysis of circulating tumor DNA to monitor metastatic breast cancer. N Engl J Med. 2013; 368:1199-1209.

47. Goto T, Hirotsu Y, Oyama T, Amemiya K, Omata M. Analysis of tumor-derived DNA in plasma and bone marrow fluid in lung cancer patients. Med Oncol. 2016; 33:29.

48. Rizvi NA, Hellmann MD, Snyder A, Kvistborg P, Makarov V, Havel JJ, Lee W, Yuan J, Wong P, Ho TS, Miller ML, Rekhtman N, Moreira AL, et al. Cancer immunology. Mutational landscape determines sensitivity to PD-1 blockade in non-small cell lung cancer. Science. 2015; 348:124-128.

49. Edwards SL, Brough R, Lord CJ, Natrajan R, Vatcheva R, Levine DA, Boyd J, Reis-Filho JS, Ashworth A. Resistance 
to therapy caused by intragenic deletion in BRCA2. Nature. 2008; 451:1111-1115.

50. Maheswaran S, Sequist LV, Nagrath S, Ulkus L, Brannigan B, Collura CV, Inserra E, Diederichs S, Iafrate AJ, Bell DW, Digumarthy S, Muzikansky A, Irimia D, et al. Detection of mutations in EGFR in circulating lung-cancer cells. N Engl J Med. 2008; 359:366-377.

51. Misale S, Yaeger R, Hobor S, Scala E, Janakiraman M, Liska D, Valtorta E, Schiavo R, Buscarino M, Siravegna G, Bencardino K, Cercek A, Chen CT, et al. Emergence of KRAS mutations and acquired resistance to anti-EGFR therapy in colorectal cancer. Nature. 2012; 486:532-536.

52. Norquist B, Wurz KA, Pennil CC, Garcia R, Gross J, Sakai W, Karlan BY, Taniguchi T, Swisher EM. Secondary somatic mutations restoring BRCA1/2 predict chemotherapy resistance in hereditary ovarian carcinomas. J Clin Oncol. 2011; 29:3008-3015.

53. Schiavon G, Hrebien S, Garcia-Murillas I, Cutts RJ, Pearson A, Tarazona N, Fenwick K, Kozarewa I, LopezKnowles E, Ribas R, Nerurkar A, Osin P, Chandarlapaty S, et al. Analysis of ESR1 mutation in circulating tumor DNA demonstrates evolution during therapy for metastatic breast cancer. Sci Transl Med. 2015; 7:313ra182.

54. Tsui DW, Berger MF. Profiling non-small cell lung cancer: from tumor to blood. Clin Cancer Res. 2016; 22:790-792.

55. Clinical Lung Cancer Genome Project (CLCGP); Network Genomic Medicine (NGM). A genomics-based classification of human lung tumors. Sci Transl Med. 2013; 5:209ra153.

56. Rudin CM, Durinck S, Stawiski EW, Poirier JT, Modrusan Z, Shames DS, Bergbower EA, Guan Y, Shin J, Guillory J,
Rivers CS, Foo CK, Bhatt D, et al. Comprehensive genomic analysis identifies SOX2 as a frequently amplified gene in small-cell lung cancer. Nat Genet. 2012; 44:1111-1116.

57. Peifer M, Fernandez-Cuesta L, Sos ML, George J, Seidel D, Kasper LH, Plenker D, Leenders F, Sun R, Zander T, Menon R, Koker M, Dahmen I, et al. Integrative genome analyses identify key somatic driver mutations of small-cell lung cancer. Nat Genet. 2012; 44:1104-1110.

58. Imielinski M, Berger AH, Hammerman PS, Hernandez B, Pugh TJ, Hodis E, Cho J, Suh J, Capelletti M, Sivachenko A, Sougnez C, Auclair D, Lawrence MS, et al. Mapping the hallmarks of lung adenocarcinoma with massively parallel sequencing. Cell. 2012; 150:1107-1120.

59. Govindan R, Ding L, Griffith M, Subramanian J, Dees ND, Kanchi KL, Maher CA, Fulton R, Fulton L, Wallis J, Chen K, Walker J, McDonald S, et al. Genomic landscape of non-small cell lung cancer in smokers and neversmokers. Cell. 2012; 150:1121-1134.

60. Hirotsu Y, Nakagomi H, Sakamoto I, Amemiya K, Oyama T, Mochizuki H, Omata M. Multigene panel analysis identified germline mutations of DNA repair genes in breast and ovarian cancer. Mol Genet Genomic Med. 2015; 3:459-466.

61. Hirotsu Y, Nakagomi H, Sakamoto I, Amemiya K, Mochizuki H, Omata M. Detection of BRCA1 and BRCA2 germline mutations in Japanese population using nextgeneration sequencing. Mol Genet Genomic Med. 2015; 3:121-129. 